\title{
Formation Mechanism of Micro Defect in Anisotropic Etching Analyzed by using Quasi-defect Pattern
}

\author{
Junji Miyazaki and Akira Kawai \\ Department of Electric Engineering, Nagaoka University of Technology \\ 1603-1 Kamitomioka, Nagaoka, Niigata 940-2188, Japan
}

\begin{abstract}
Anisotropic wet etching for Si substrate is a key technology for manufacturing three dimensional structures for MEMS. It is important to understand a printability of defect during this etching process to create a complete design of MEMS structure. In this paper, an impact of quasi-defects on an etched structure is investigated. It is demonstrated that a minimum defect size which is not affect on the final structure is around a half of total etching depth.
\end{abstract}

Keywords: Anisotropic etching, defect, photo lithography, MEMS, Si wafer

\section{Introduction}

Micro Electro Mechanical Systems (MEMS) is a key technology to integrate machine, sensor, actuator or electric circuit into one device. It is already applied to such as gyroscope, acceleration sensor or digital mirror device ${ }^{[1,2]}$.One method to fabricate MEMS device is to apply a process technology which has been already developed for LSI manufacturing. A single crystalline of silicon which is used for this process has an anisotropic etching property for strong alkaline wet etching process. This property easily enables to fabricate a three dimensional structure into a Si substrate. It is not a new technology, but useful technology because it is simple and low cost process, but it enables to construct a complex three dimensional structure.

Photolithography is used to create an etching mask. Defect control is one of key technology for photolithography. It is important to know a printability of defect during this etching process. However it is difficult to predict an impact of defect during anisotropic etching.

In this paper, an impact of quasi-defect on an etched $\mathrm{Si}$ substrate is studied. Etched window shape using anisotropic wet etching on Si substrate is shown in Fig.1. Preparing quasi-defect on oxide mask, we investigated defects printability and demonstrated minimum defect size which is not affect on the final structure.

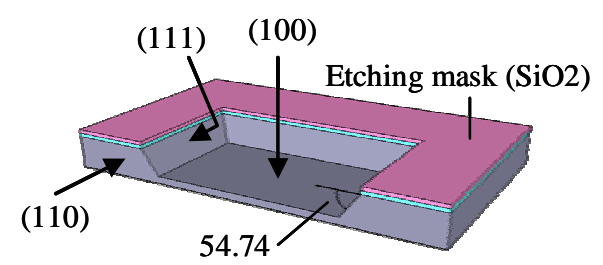

(a) Shape of anisotropic etched window

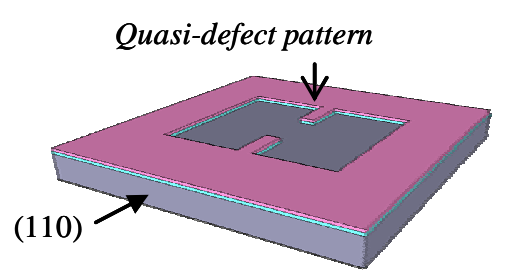

(b) $0^{\circ}$ rotated pattern

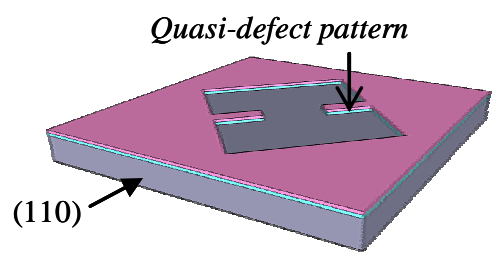

(c) $45^{\circ}$ rotated pattern

Fig. 1 Schematic diagram of Quasi-defect pattern. 


\section{Experiment}

Several quasi-defects were prepared in a thermal oxide film as a etching mask to evaluate a printability of these defects by using EPW anisotropic etching into Si substrate.

\subsection{Thermal oxide film}

A Si substrate was oxidized by using an electric furnace after removing native oxide layer by $\mathrm{HF}$ treatment. Temperature profile was shown in Fig.2. The substrates of $12 \mathrm{~mm} \times 12 \mathrm{~mm}$ size were used. $\mathrm{SiO}_{2}$ thickness measured by Elipsometry was also shown in Fig.2.

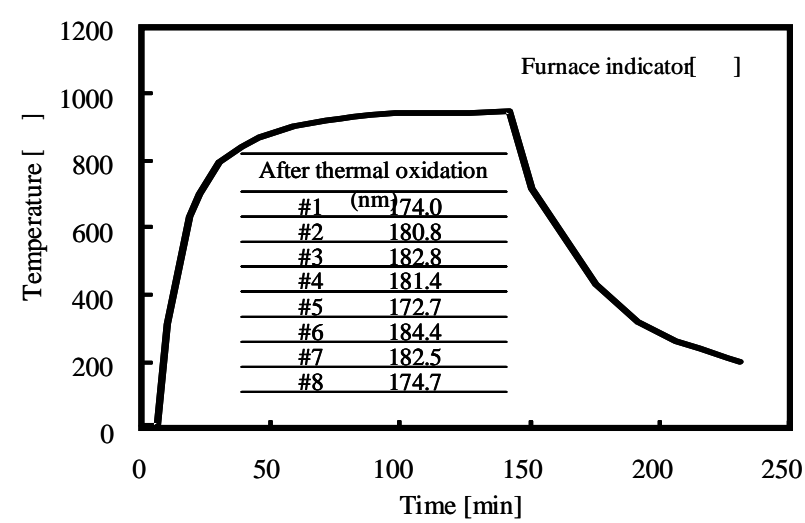

Fig.2 Temperature profile for thermal oxidation.

\subsection{Photomask with quasi-defects}

Several design of quasi-defects of which width is from $10 \mu \mathrm{m}$ to $50 \mu \mathrm{m}$ were employed on a photo mask. Lithography conditions and a top view of the photomask were summarized in Table 1.

Table 1 Conditions for photo mask preparation.

\begin{tabular}{cc}
\hline F value & 22 \\
\hline Focus & 50 \\
\hline Shutter & Open \\
\hline Exposure time & $2 \mathrm{~min}$ \\
\hline Developer & $5 \mathrm{~min}$ \\
\hline Rinse & $20 \mathrm{sec}$ \\
\hline Fixer & $2 \mathrm{~min}$ \\
\hline Water washing & $15 \mathrm{~min}$ \\
\hline
\end{tabular}

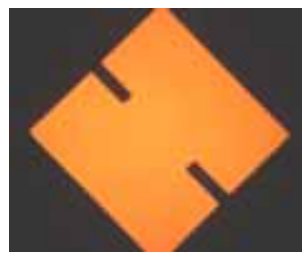

\subsection{Substrate etching}

Figure 3 showed a process flow of anisotropic etching. Resist film was coated on a Si substrate with oxide layer. (2): Quasi-defects on the photomask were printed into resist film on oxide layer by using photolithography. Lithographic conditions were shown in Table 2. (3): Defect
(1)

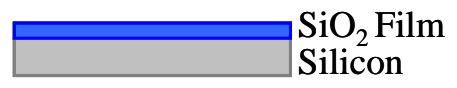

(2)
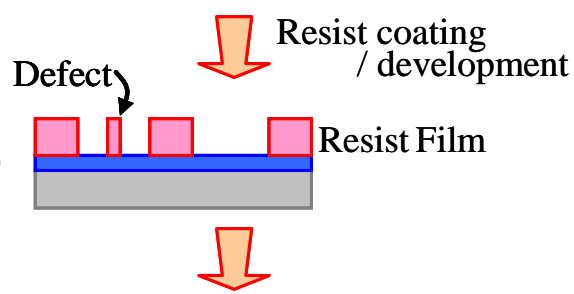

(3)

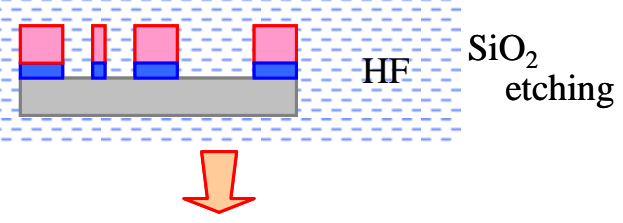

(4)

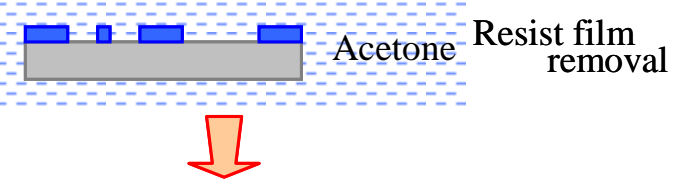

(5)

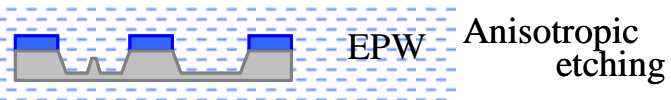

Fig.3 Flow chart of anisotropic etching.

patterns were etched into the silicon dioxide layer by HF wet etching. The substrates were inserted into $5 \%$ of $\mathrm{HF}$ solution for $3 \mathrm{~min}$. Etching rate measured was $0.54 \mathrm{~nm} / \mathrm{sec}$. The $\mathrm{SiO}_{2}$ mask with defects was created into the oxide layer during wet etching. After removing the resist film, anisotropic etching with $\mathrm{SiO}_{2}$ mask was treated by using the EPW solution. The EPW etching conditions were summarized in Table 3.

Table 2 Lithographic conditions.

\begin{tabular}{ccc}
\hline HMDS & Vapor & $1 \mathrm{hr}$ \\
\hline HMDS-Bake & $120^{\circ} \mathrm{C}$ & $5 \mathrm{~min}$ \\
\hline \multirow{2}{*}{ Resist coating } & $500 \mathrm{rpm}$ & $5 \mathrm{sec}$ \\
\cline { 2 - 3 } & $3000 \mathrm{rpm}$ & $30 \mathrm{sec}$ \\
\hline Pre-bake & $90^{\circ} \mathrm{C}$ & $5 \mathrm{~min}$ \\
\hline Exposure & \multicolumn{2}{c}{$2.5 \mathrm{sec}$} \\
\hline Development & $\mathrm{TMAH} 2.38 \%$ & $22 \mathrm{sec}$ \\
\hline Rinse & DI-Water & $10 \mathrm{sec}$ \\
\hline Hard-bake & $150{ }^{\circ} \mathrm{C}$ & $5 \mathrm{~min}$ \\
\hline
\end{tabular}

Table 3 EPW etching conditions.

\begin{tabular}{llcr}
\hline Etching & Ethylenediamine & $\mathrm{NH}_{2}\left(\mathrm{CH}_{2}\right)_{2} \mathrm{NH}_{2}$ & $46.4 \mathrm{~mol} \%$ \\
Solution & Pyrocatechol & $\mathrm{C}_{6} \mathrm{H}_{4}(\mathrm{OH})_{2}$ & $4.0 \mathrm{~mol} \%$ \\
(EPW) & DI-water & $\mathrm{H}_{2} \mathrm{O}$ & $49.6 \mathrm{~mol} \%$ \\
\hline Temperature & $85{ }^{\circ} \mathrm{C} \pm 5{ }^{\circ} \mathrm{C}$ \\
\hline Process time & $60 \mathrm{~min}$ \\
\hline
\end{tabular}


Etching rate was calculated from window size before and after etching as shown in Fig.4. It was observed that a diagonal shape of window became an octagonal shape because of a different etching rate of $\mathrm{Si}(100)$ from $\mathrm{Si}(110)$. The mask window of $531 \mu \mathrm{m}$ became $712 \mu \mathrm{m}$ after $150 \mathrm{~min}$ EPW etching. Etching rate is $0.6 \mu \mathrm{m} / \mathrm{min}$ for $\mathrm{Si}[110]$ direction.

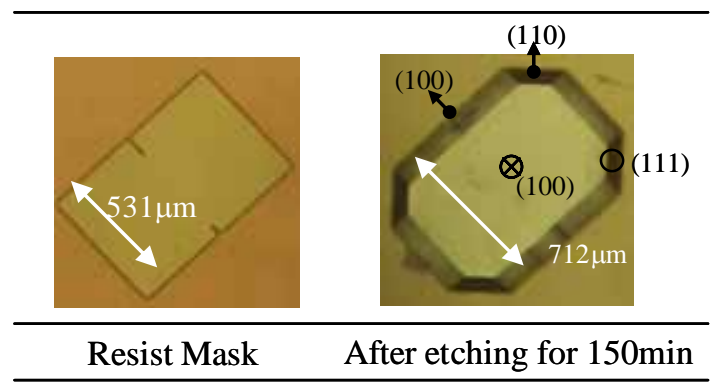

Fig. 4 Mask window width before and after anisotropic etching.

\section{Results and Discussion}

Figures $5 \mathrm{a}$ and $5 \mathrm{~b}$ show top view of samples before and after EPW etching respectively. Mask direction was parallel to Si (110). It was found that defects were remained when the defect was larger than $16.3 \mu \mathrm{m}$. It was also investigated using 45 degree rotated mask. Results were show in Fig.6a and $6 \mathrm{~b}$. It is clearly demonstrated that defects were remained when the defect was larger than $10.9 \mu \mathrm{m}$.

Figure 7 shows etching time dependency of defect formation. It was observed that $30 \mu \mathrm{m}$ of the defect was remained until $60 \mathrm{~min}$ and removed after 90 min.

It is estimated that the defects are removed in the following step. The etching rate at the edge of a defect is assumed a half of that at flat plane, since

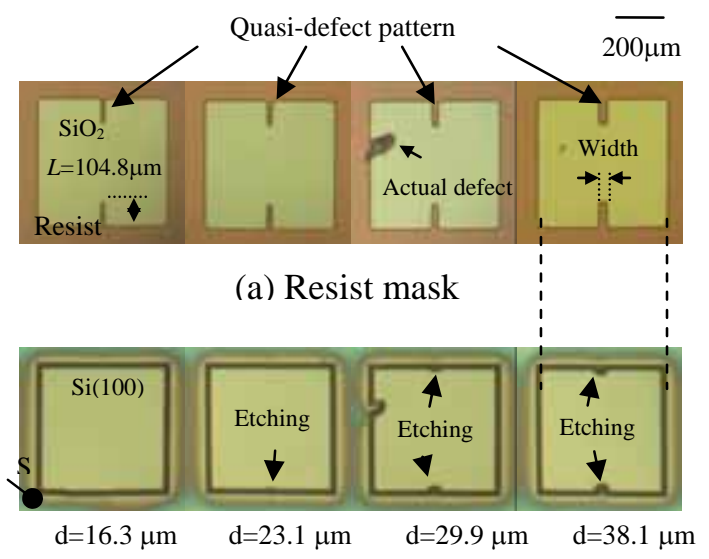

(b) After etching

Fig.5 Etched defect shape for non-rotated mask.

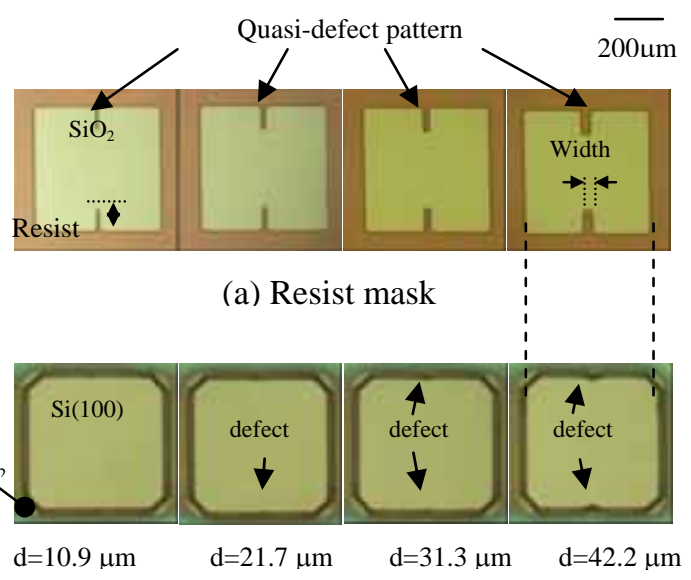

(b) After etching

Fig.6 Etched defect shape for 45 degree rotated mask.

the area that the etching species can attack the $\mathrm{Si}$ surface. When the defect is lifting off, the etching rate becomes two times as fast as that of the flat plane since the top of defect has two times wider area which the etching species can attack. The main part of defect will disappear after a half of total etching time. This estimation means the defect of which size is smaller than the half of total etching depth cannot be printed. It can be predicted that a limit of printable defect size is $18 \mu \mathrm{m}$ for 60 min etching and $27 \mu \mathrm{m}$ for 90 min etching.

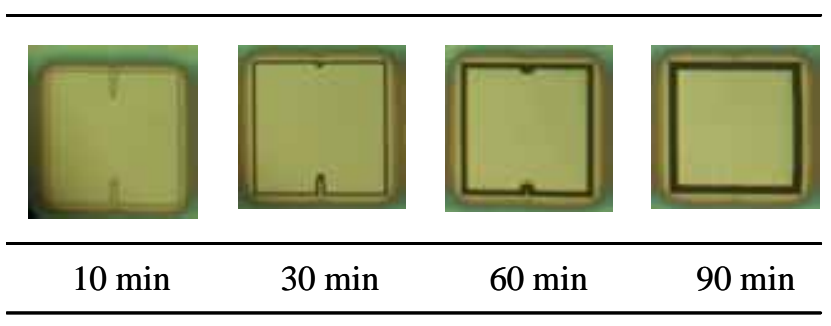

Fig. 7 Time dependency for defect formation. Defect width $=30 \mu \mathrm{m}$, no-rotated mask

\section{Conclusion}

An impact of defects during anisotropic etching for Si substrate is investigated. A defect printability is observed using quasi-defect on an oxide mask. It is found that a defect of around $10 \mu \mathrm{m}$ width is not printed into $\mathrm{Si}$ substrate in case of $60 \mathrm{~min}$ of EPW wet etching. It is demonstrated that a minimum defect size which couldn't affect on the final structure is determined as around a half of total etching depth. 


\section{Acknowledgement}

The present work was partially supported by Grant-In-Aid Scientific Research from Japan Society for the Promotion of Science (Scientific Research (B) 19360157).

\section{References}

1.M.Shikida, IEEJ Trans.SM, 128 (2008) 341.

2.N.Maluf, K.Williams, "An Introduction to

Microelectromechanical System Engineering, SECOND EDTION”, (2004) 47. 